\title{
Alternative Reducing Agents in Metallurgical Processes: Devolatilization of Shredder Residue Materials
}

\author{
Samira Lotfian $^{1} \cdot$ Hesham Ahmed ${ }^{1,2} \cdot$ Caisa Samuelsson $^{1}$
}

Published online: 20 October 2016

(c) The Author(s) 2016. This article is published with open access at Springerlink.com

\begin{abstract}
Plastic-containing shredder residue material has the potential to be used as an alternative reducing agent in nonferrous bath smelting processes. This would lead to not only decreased dependency on primary sources such as coal or coke but also to an increase in the efficiency of utilization of secondary sources. This calls for systematic scientific investigations, wherein these secondary sources are compared with primary sources with respect to devolatilization characteristics, combustion characteristics, reactivity, etc. As a first step, in this paper, devolatilization characteristics of plastic-containing shredder residue material (SRM) are compared to those of coal using thermogravimetric analysis. Proximate analysis has shown that SRM mainly decomposes by release of volatiles, while coal shows high fixed carbon content, which is reported to contribute to reduction reactions. To study the reduction potential of the evolved materials, composition of evolved off-gas was continuously monitored using quadrupole mass spectroscopy. The composition of volatiles shows $\mathrm{H}_{2}, \mathrm{CO}$, and hydrocarbons which are known to have reduction potential. Therefore, it is essential that SRM would be used in a process that could
\end{abstract}

The contributing editor for this article was Brajendra Mishra.

Samira Lotfian

samira.lotfian@1tu.se

Hesham Ahmed

hesham.ahmed@1tu.se

Caisa Samuelsson

caisa.samuelsson@1tu.se

1 MiMer, Luleå University of Technology, 97187 Luleå, Sweden

2 Central Metallurgical Research \& Development Institute (CMRDI), Cairo, Egypt utilize the evolved volatiles for reduction. Furthermore, to understand the potentials of different plastic materials as reducing agents, the devolatilization mechanisms and volatile composition of three common plastics, namely, polyethylene, polyurethane, and polyvinylchloride and their mixtures have been studied. The results show the interaction between the plastics within the binary and ternary mixtures. Similar phenomena may occur during devolatilization of SRM, which contains different type of plastics.

Keywords Devolatilization - Shredder residue material · Plastic - Coal · Thermogravimetry · Alternative reducing agent

\section{Introduction}

Shredder residue material (SRM) is the residue from the shredding of end-of-life equipment such as automotive or discarded electrical and electronic equipment [1]. End-oflife equipment is fed into hammer mills, which reduces all parts in size; these parts are then separated using an array of processes such as air classification, magnetic and eddy current separators into three major streams: ferrous, nonferrous scraps, and a light fraction which mainly consist of plastics called SRM. Ferrous and nonferrous fractions are recycled in metallurgical plants for recovery of metals [2]. The fraction with low metal value and high fraction of plastics is considered to be more problematic due to its complexity and low economic value. Unfortunately, conventional mechanical recycling which is common choice for recycling of packing materials (e.g., polyethylene terephthalate or high density polyethylene) is not applicable to SRM. This is due to the fact that in electronic equipment, 15-20 different types of plastics may be used 
containing a variety of plasticizers, colorants, flame retardants, and fillers, in addition to a fraction of metals and ceramics [3]. One way to utilize this material is as a reducing agent in metallurgical processes. Plastics are composed of long polymeric chains of carbon and hydrogen; for this reason, they are potential candidates to substitute the traditionally used reducing agents [4]. Utilizing residue materials in general and, specifically SRM in metallurgical processes not only reduces the dependency on the fossil coal, but can also lead to a more sustainable way to manage these materials $[5,6]$.

The usage of plastic materials as a source of reducing agent in the iron and steel-making industry has been reported both in research and on the industrial level. $[1,4,7,8]$ JFE Steel in Japan has reported the use of plastic in their blast furnace since 1996. Plastic injection has been developed by Bremer Stahlwerke in Germany, with more than 50,000 tons of plastics injected in their blast furnace [4]. However, one limitation in using plastic-containing residue material for iron making is the presence of associated impurity metals such as copper, which is undesirable in the iron-making process [1]. Such restrictions do not apply for nonferrous bath-smelting processes, which makes them appealing for utilization of SRM. For nonferrous processes, in which coal is used as a reductant, it is known that coal contributes to reduction through the gasification reaction of carbon in char $[9,10]$. However, plastics are known to decompose by low amount of char and high amount of volatiles. Studies on the utilization of plastic material in blast furnace reported generation of $\mathrm{C} 1-\mathrm{C} 4$ hydrocarbons, $\mathrm{H}_{2}$, and $\mathrm{CO}$, which can participate in reduction reactions $[4,11]$. Thus, prior to utilizing SRM as an alternative reducing agent, a deep understanding of the thermal decomposition of SRM in comparison with coal as current reducing agent is needed for process optimization.

The present paper is devoted to studying the devolatilization of shredder residue material in comparison with coal using a thermogravimetric analyzer. In order to investigate the devolatilization mechanism, the composition of volatiles released during devolatilization is determined using quadrupole mass spectroscopy. SRM consists of a mixture of different plastic materials and other impurity elements, which brings heterogeneity and complexity to its devolatilization. Therefore, to gain a better understanding on potential of plastic materials as reducing agent, devolatilizations of three common plastics, namely, polyethylene (PE), polyvinyl chloride (PVC), polyurethane (PU), and their mixture have been studied.

\section{Theoretical Background}

Depending on the molecular arrangement and bond energies, plastic materials have different thermal decomposition behaviors. Among the suggested number of decomposition mechanisms, the most common mechanisms are random-chain scission, in which chain scission occurs at apparently random locations in polymer chains; and crosslinking, in which bonds are created between two adjacent polymer chains [12].

$\mathrm{PE}$ is one of the most commonly used thermoplastics, composed of a long chain of ethylene monomers (repeated units of $\left.-\left(\mathrm{CH}_{2}-\mathrm{CH}_{2}\right)-\right)$. Bond breakage in PE occurs with random scission. Thermoplastic materials go through a molten stage during thermal decomposition. PE devolatilizes by bubble formation, which moves toward the surface and releases light products [13]. PU is a nitrogen-containing polymer; consisting of repeated units of -NH-COOThe two main constituents of PU are isocyanate and polyol. The major breakdown mechanism in PU is the scission of the polyol-isocyanate bond, to form gaseous isocyanates, and liquid polyols. A further step is the dimerization of the isocyanate to carbon dioxide $[14,15]$. PVC is a chlorinecontaining polymer with repeated units of $-\left(\mathrm{CH}_{2}-\mathrm{CHCl}\right)-$. Thermal decomposition of PVC proceeds in two distinct stages. Up to $360{ }^{\circ} \mathrm{C}$, dehydrochlorination is the main reaction, accompanied by release of $\mathrm{HCl}$, giving a remaining structure of polyene. Above $360{ }^{\circ} \mathrm{C}$, structural breakdown of remaining polyene structure occurs, resulting in formation of hydrocarbons and residual char [16].

\section{Materials and Methods}

A plastic-containing SRM (generated from shredding electrical and electronic equipment) and a coal sample as reference material for comparison were selected. Three individual plastics were selected, namely PE, PU, and PVC. SRM and individual plastics were crushed to less than $0.5 \mathrm{~mm}$, and the coal sample was pulverized to less than $38 \mu \mathrm{m}$. Crushing the SRM particles to less than $0.5 \mathrm{~mm}$ leads to segregation using the current method, due to different grinding abilities of contained materials. Devolatilization of coal sample with particle sizes ranging from $38 \mu \mathrm{m}$ up to $0.5 \mathrm{~mm}$ has been studied; no significant differences in devolatilization of different particle sizes were observed.

\section{Characterization}

Proximate and ultimate analyses based on standard methods ${ }^{1}$ were carried out for all samples, by the certified

\footnotetext{
${ }_{1}$ Standards for proximate analysis of coal: Moisture SS 187155, ash SS 185157, volatile SS-ISO 562:2010. Standards for proximate analysis of SRM: Moisture SS-EN 14774:2009, ash SS-EN 14775:2009, volatile SS-EN 15148:2009. Fixed carbon was calculated. Ultimate analysis standard for coal: CHN ASTM D5373, Sulfur SS 187177, Oxygen calculated, Ultimate analysis standard for SRM: CHN SS-EN 15104:2011, Oxygen calculated.
} 


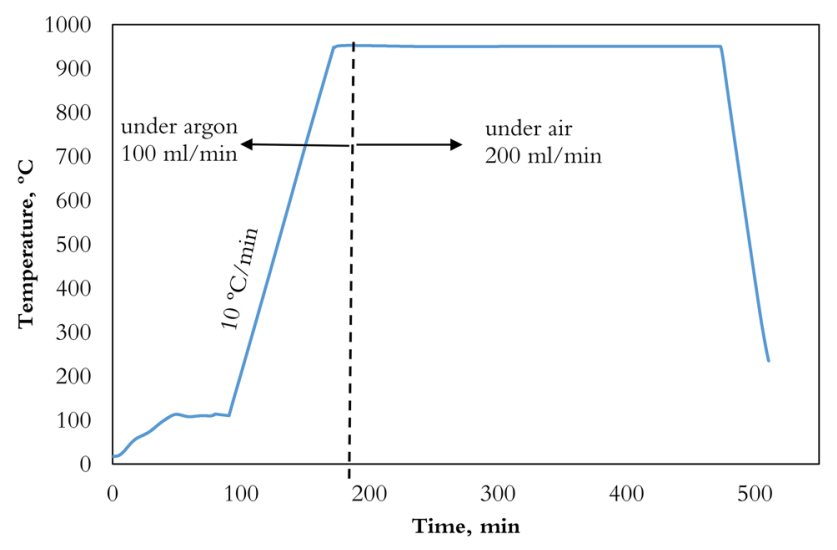

Fig. 1 Heating cycle during proximate analysis using TGA

laboratory, ALS Scandinavia AB, Sweden. Ultimate analysis was done to determine the elemental compositions of samples, namely, C, H, N, O, and S. Proximate analysis was used to determine moisture, volatile matter, ash, and fixed carbon content.

To determine the representativeness of the results, especially for SRM, which is a heterogeneous material, proximate analysis was also performed using a thermal gravimetric analyzer (TGA). The experiment, as shown in Fig. 1, involves heating of $20 \mathrm{mg}$ of samples under an inert atmosphere of Argon, at a heating rate of $10{ }^{\circ} \mathrm{C} / \mathrm{min}$ from room temperature to $110{ }^{\circ} \mathrm{C}$, the samples were kept at this temperature for $10 \mathrm{~min}$ to remove residual moisture. Afterward, the samples were heated up to $950{ }^{\circ} \mathrm{C}$ still under an inert atmosphere of Argon; the weight loss observed in this stage is associated with volatile content. Finally, the sample was kept at a temperature of $950{ }^{\circ} \mathrm{C}$ for $5 \mathrm{~h}$, while the atmosphere was changed from Argon to air. Since this stage involves oxidation of carbon, the weight loss observed is associated with the fixed carbon content of material, and remaining material represents ash [17]. The experiment was repeated five times, for determining the reproducibility of results.

\section{Devolatilization Experiment}

Devolatilization experiments were carried out using a Netzsch Thermal Analyzer STA 409 instrument with sensitivity of $\pm 1 \mu \mathrm{g}$. The device is coupled with a quadrupole mass spectroscometer (QMS) to analyze the evolved gases. A schematic figure of the thermal analysis instrument is given in Fig. 2. In a mass spectrometer, compounds are ionized and separated based on mass/charge $(\mathrm{m} / \mathrm{z})$ ratio. The number of ions representing each mass/charge ratio is recorded. For example, mass spectra of $\mathrm{H}_{2} \mathrm{O}$ show the molecular ion at $\mathrm{m} / \mathrm{z}$ of 18 , and include numerous fragment peaks for $\mathrm{m} / \mathrm{z}$ ratios in the range of 2-16 [18]. During devolatilization experiments, mass spectroscopy monitors the off-gas composition online for the mass/charge ratio numbers in the range of 1-100. The presented values are used only for qualitative analysis of released species.

$20 \mathrm{mg}$ of the sample was placed in the TGA and heated up to $900{ }^{\circ} \mathrm{C}$ at a heating rate of $10^{\circ} \mathrm{C} / \mathrm{min}$ as shown in Fig. 3. All experiments were performed under an Argon atmosphere with a flow rate of $100 \mathrm{ml} / \mathrm{min}$ to avoid oxidation of char or evolved volatiles. Based on preliminarily experiments, the following experimental conditions were chosen to minimize the interference of heat and mass transfer [19]. Small amount of sample, $20 \mathrm{mg}$; shallow crucible height, $3 \mathrm{~mm}$; and high flow rate, $100 \mathrm{ml} / \mathrm{min}$.

\section{Results and Discussion}

\section{Characterization of Samples}

The proximate and ultimate analyses of SRM and coal are summarized in Table 1. Ultimate analysis shows that the carbon content of SRM is lower than that in coal, while its hydrogen content is slightly higher, with both elements indicating the reduction potential of this material. The proximate analysis shows that coal mainly decomposes forming char; the fixed carbon content of char is known to contribute to reduction [9]. In contrast to the composition of coal, the fixed carbon content of SRM char is low. SRM decomposes with a significantly higher amount of volatiles compared with coal; therefore, it is important that the volatile content of SRM participates in reduction reactions. SRM has higher content of ash compared with coal, due to the presence of metals and ceramic materials. Due to the heterogeneous nature of SRM, proximate analysis was performed using TGA for comparison with the standard method analysis; the results are shown in Table 1.

Ultimate and proximate analyses of individual plastics (PE, PU, and PVC) are presented in Table 2 which shows the diversity in the characteristics of the studied plastics and, possibly, for plastics present in SRM. PE shows the highest hydrogen and carbon contents, compared with the other plastics. The carbon content of PE is similar to that of coal, while the hydrogen content is even higher than that for coal. Based on this result, it is possible to assume that PE could have the same reduction potential as coal. The main difference, however, is the proximate analysis, where PE decomposes by release of approximately $94 \%$ volatiles. PU and PVC have lower carbon and hydrogen contents, compared with PE and coal. In addition, they both have high oxygen contents, which might affect their reduction potential. All the three plastics show high volatile content, with the trend being in the decreasing order: 
Fig. 2 Schematic figure of TGA/QMS

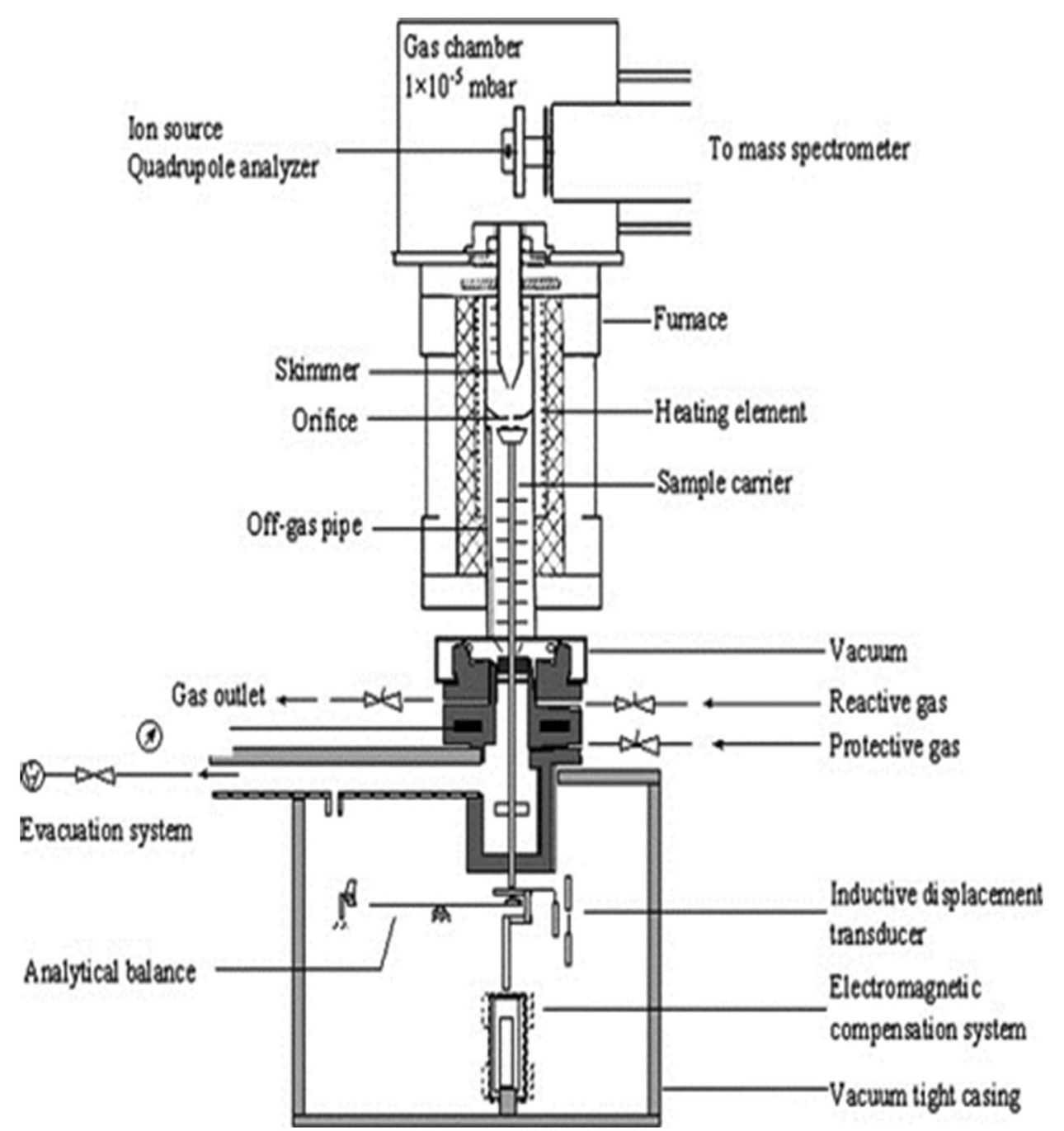

$\mathrm{PE}>\mathrm{PU}>\mathrm{PVC}$; these results are in agreement with studies reported by other researchers [13, 15, 16]. Similar to SRM, all three types of these plastics can be described by high volatile contents and relativeley low fixed carbon compared with coal.

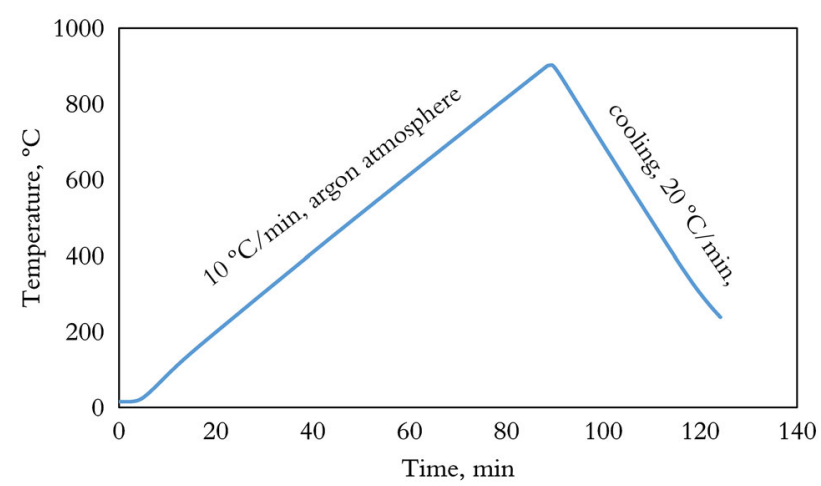

Fig. 3 Heating cycle during devolatilization experiments using TGA

\section{Devolatilization of SRM and Coal}

Figures 4a and 5a show the weight loss for coal and SRM during devolatilization. Devolatilization of coal starts at $450{ }^{\circ} \mathrm{C}$ and continues gradually up to $800{ }^{\circ} \mathrm{C}$, while, in case of SRM, it starts at around $250{ }^{\circ} \mathrm{C}$ and ends at $450{ }^{\circ} \mathrm{C}$. The first derivative of the weight percent curves with respect to time is plotted and shown as a derivative thermogravimetric (DTG) curve. It represents mass loss rate versus time and indicates the temperature at which different stages are taking place [12]. For coal, the maximum reaction rate is indicated by a maximum at $480{ }^{\circ} \mathrm{C}$, indicating that coal devolatilizes in one gradual stage. Devolatilization of SRM shows two stages; the first one occurs at approximately $280{ }^{\circ} \mathrm{C}$, and the second peak seems to consist of two overlapping peaks at 350 and $400{ }^{\circ} \mathrm{C}$. Day et al. [3] have studied the devolatilization of several plastics used in electronic industry and have reported a substantial difference in weight loss curves of these plastics. The presence of several stages during SRM 
Table 1 Results from ultimate and proximate analyses, for coal and shredder residue materials

\begin{tabular}{|c|c|c|c|c|c|c|}
\hline & $\mathrm{H}(\mathrm{wt} \%)$ & $\mathrm{O}(\mathrm{wt} \%)$ & $\mathrm{N}(\mathrm{wt} \%)$ & $\mathrm{S}(\mathrm{wt} \%)$ & $\mathrm{C}(\mathrm{wt} \%)$ & Ash (wt\%) \\
\hline \multicolumn{7}{|l|}{ Ultimate analysis } \\
\hline Coal & 4.8 & 5.2 & 1.3 & 0.3 & 84.0 & 4.4 \\
\hline \multirow[t]{2}{*}{ Shredder residue material } & 6.1 & 12.0 & 1.7 & 0.1 & 56.9 & 23.2 \\
\hline & \multicolumn{2}{|c|}{ Moisture (wt\%) } & Volatile (wt\%) & \multicolumn{2}{|c|}{ Fixed carbon (wt $\%)$} & Ash $(w t \%)$ \\
\hline \multicolumn{7}{|c|}{ Proximate analysis according to standards } \\
\hline Coal & 0.8 & \multicolumn{2}{|c|}{26.5} & \multicolumn{2}{|l|}{66.4} & 6.3 \\
\hline Shredder residue material & 0.7 & \multicolumn{2}{|c|}{71.5} & \multicolumn{2}{|l|}{3.3} & 24.5 \\
\hline \multicolumn{7}{|l|}{ Proximate analysis using TGA } \\
\hline Coal & $0.4 \pm 0.3$ & & $22.7 \pm 0.4$ & \multicolumn{2}{|c|}{$66.7 \pm 1.6$} & $9.5 \pm 2.4$ \\
\hline Shredder residue material & $0.6 \pm 0.3$ & & $66.9 \pm 5.2$ & \multicolumn{2}{|c|}{$9.3 \pm 1.9$} & $23.2 \pm 6.3$ \\
\hline
\end{tabular}

\begin{tabular}{|c|c|c|c|c|c|c|c|}
\hline & $\mathrm{H}(\mathrm{wt} \%)$ & $\mathrm{O}(\mathrm{wt} \%)$ & $\mathrm{N}(\mathrm{wt} \%)$ & $\mathrm{S}(\mathrm{wt} \%)$ & $\mathrm{C}(\mathrm{wt} \%)$ & $\mathrm{Cl}(\mathrm{wt} \%)$ & Ash $(\mathrm{wt} \%)$ \\
\hline \multicolumn{8}{|c|}{ Ultimate analysis according to standards } \\
\hline PE & 14.0 & $<1$ & $<0.1$ & 0.01 & 84.4 & - & 1.6 \\
\hline PU & 6.7 & 16.9 & 5.8 & 0.03 & 62.9 & - & 7.7 \\
\hline \multirow[t]{2}{*}{ PVC } & 4.8 & 20.2 & $<0.1$ & 0.03 & 38.5 & 13.3 & 23.2 \\
\hline & \multicolumn{2}{|c|}{ Moisture (wt\%) } & \multicolumn{2}{|c|}{ Volatile (wt\%) } & \multicolumn{2}{|c|}{ Fixed carbon (wt $\%)$} & Ash (wt\%) \\
\hline \multicolumn{8}{|c|}{ Proximate analysis using TGA } \\
\hline $\mathrm{PE}$ & 1.0 & & 94.3 & & 2.6 & & 2.1 \\
\hline PU & 1.6 & & 73.6 & & 14.5 & & 10.3 \\
\hline PVC & 1.2 & & 62.9 & & 12.6 & & 23.3 \\
\hline
\end{tabular}

Table 2 Results from ultimate and proximate analyses of individual plastics compounds (such as $\mathrm{CH}_{4}$ ) and water. The aromatic compounds diffuse slowly, even at high temperature and recombine by release of hydrogen [20], as shown by following equation, in which $R$ represents aromatic compounds.

$\mathrm{RH}+\mathrm{HR}^{\prime} \rightarrow \mathrm{RR}^{\prime}+\mathrm{H}_{2}$

The trend of volatile release for SRM is more complicated compared with coal. Several phenomena occur, which can be summarized as follows:

1. Initially, $\mathrm{H}_{2} \mathrm{O}$ and $\mathrm{HCl}$ start to evolve at $250{ }^{\circ} \mathrm{C}$, which continues up to $320{ }^{\circ} \mathrm{C}$; this temperature range corresponds to the first DTG peak observed.

2. $\mathrm{CO}_{2}$ release also starts at $250{ }^{\circ} \mathrm{C}$, reaching a peak at about $320{ }^{\circ} \mathrm{C}$ but continues up to $500{ }^{\circ} \mathrm{C}$. In this temperature range, $\mathrm{CO}$ is also released.

3. Release of hydrocarbons is observed only at temperatures higher than $350{ }^{\circ} \mathrm{C}$, reaching a maximum at $400{ }^{\circ} \mathrm{C}$. Although release of hydrogen is observed throughout devolatilization, it increases at temperatures above $450{ }^{\circ} \mathrm{C}$. Hydrocarbons and hydrogen are released at higher temperatures compared with $\mathrm{CO}$, $\mathrm{CO}_{2}$, since the bond-breaking reactions of $\mathrm{C}-\mathrm{H}$ and 

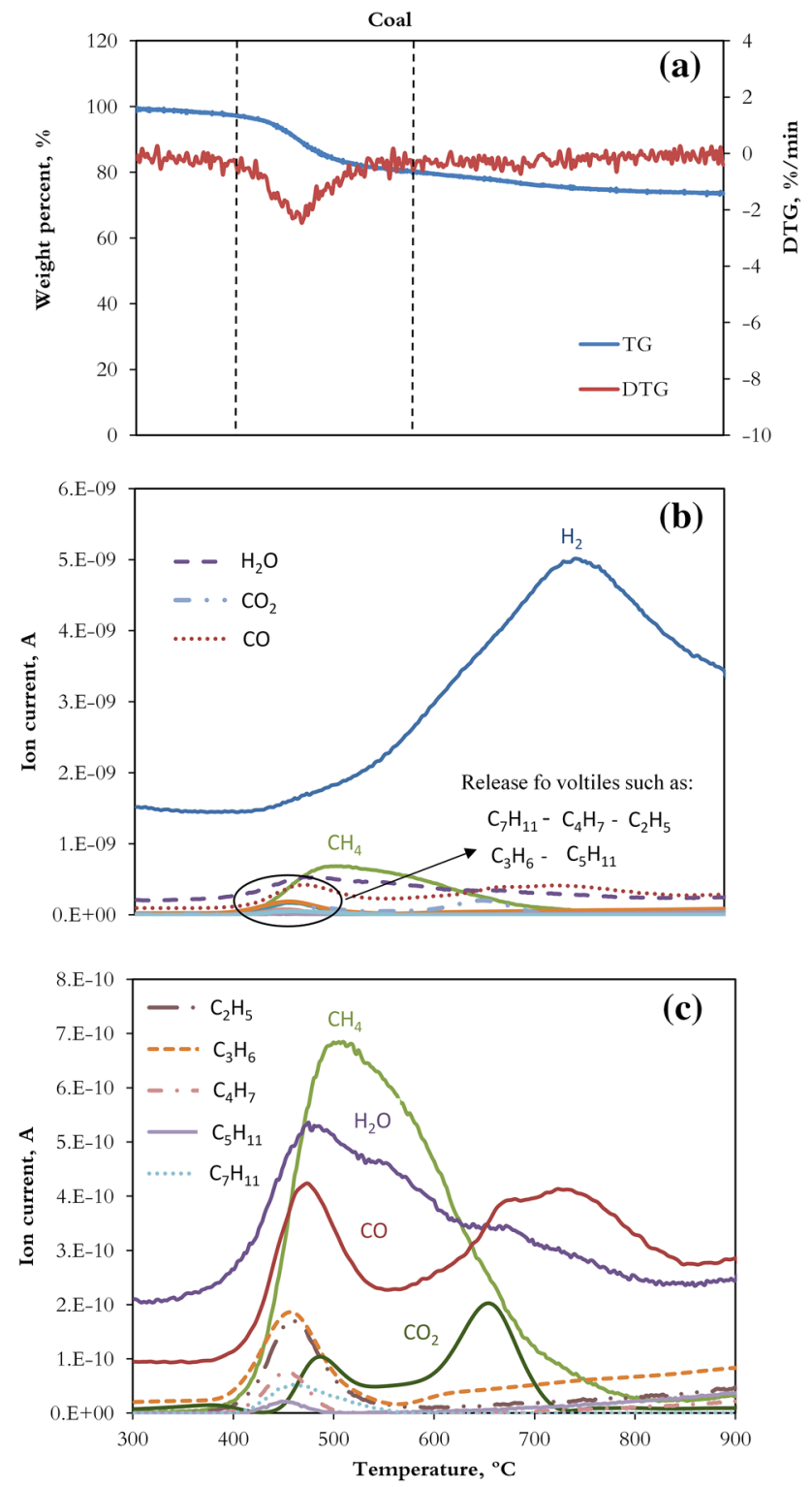

Fig. 4 a TGA, DTG curves of coal devolatilization under argon flow, at heating rate of $10{ }^{\circ} \mathrm{C} / \mathrm{min}$. b Composition of volatiles released detected by mass spectrometer. c A closer examination of volatiles released excluding hydrogen $\left(\mathrm{H}_{2}\right)$ (Color figure online)

$\mathrm{C}-\mathrm{C}$ have been reported to become thermally active at temperatures higher than $450{ }^{\circ} \mathrm{C}$ [23].

The observation of two stages during devolatilization of plastics derived from electrical and electronic equipment is in agreement with the findings of other researchers [24, 25]. Vasile et al. [24] studied devolatilization of keyboards and computer case, and reported that devolatilization starts at about $250{ }^{\circ} \mathrm{C}$, with release of halogenated compounds mainly due to presence of PVC. At temperatures higher than $370{ }^{\circ} \mathrm{C}$, releases of phenol and alkyl aromatic compounds were observed. Similar
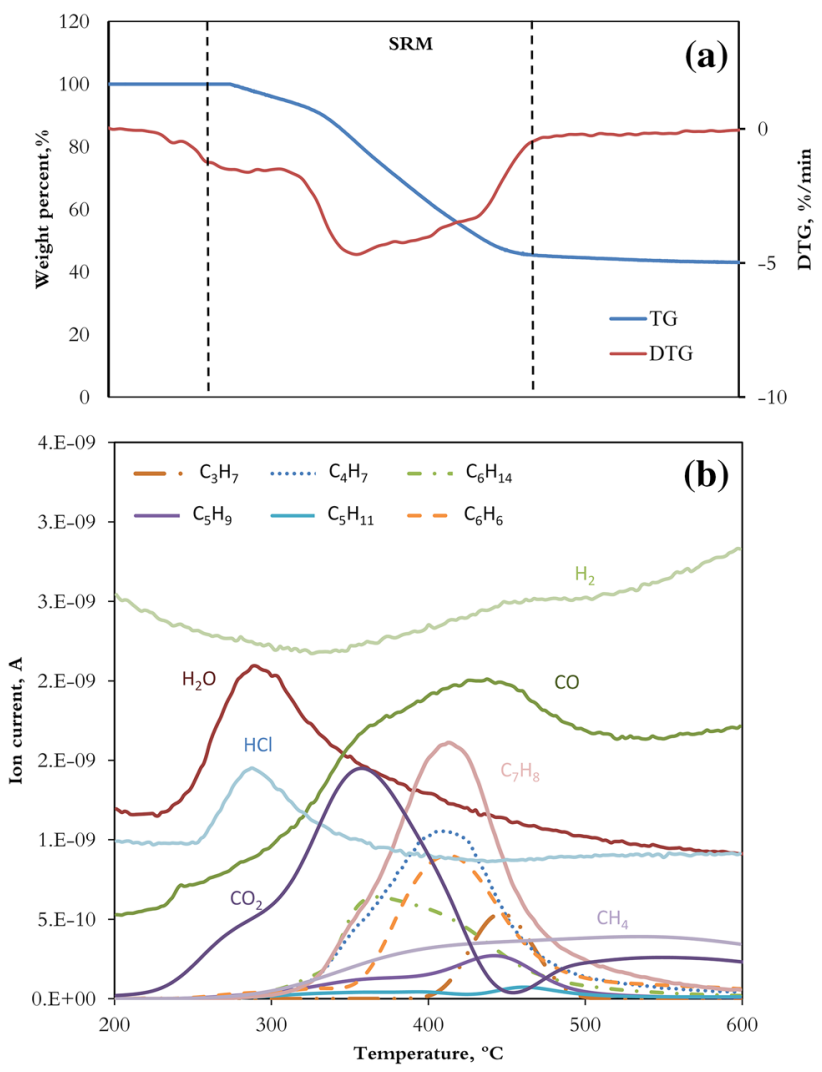

Fig. 5 a TGA, DTG curves of SRM devolatilization under argon flow, at heating rate of $10^{\circ} \mathrm{C} / \mathrm{min}$. b Composition of volatiles released as detected by mass spectrometer (Color figure online)

observation was reported for devolatilization of printed circuit board.

In addition, it was observed that SRM devolatilization leads to higher amounts of volatiles released at relatively lower temperatures, compared with coal. Devolatilization starts with the breaking-up of weaker bonds; for coal, it has been reported that first bond to break-up is $\mathrm{C}-\mathrm{C}$ bond between the ring structures and requires a temperature of $470{ }^{\circ} \mathrm{C}$ [22], which was observed in the present study. However, the bonds in plastics are weaker; for example, in $\mathrm{PVC}$, the $\mathrm{C}-\mathrm{Cl}$ bond is reported to have the lowest energy and starts to break-up at a temperature as low as $150{ }^{\circ} \mathrm{C}$ [26]. Utilization of plastic residue containing PVC is limited due to corrosive effect of $\mathrm{HCl}$ [27]. The current study shows that $\mathrm{HCl}$ is released at $250{ }^{\circ} \mathrm{C}$, while the majority of hydrocarbons are still present in the SRM. Applying a twostage devolatilization, in which material is first devolatilized at $250{ }^{\circ} \mathrm{C}$ prior to utilization in the process, would lead to a chlorine-free product that can be used without the corrosive effect.

Devolatilization of SRM, as for coal, is accompanied by releases of $\mathrm{H}_{2}$ and $\mathrm{CO}$ which can aid reduction. Furthermore, release of hydrocarbon is observed, which at temperatures prevailing in metallurgical processes will 
decompose to carbon and hydrogen [28], and probably further contribute to reduction reactions. Decomposition of hydrocarbons is accelerated by the presence of $\mathrm{H}_{2} \mathrm{O}_{(\mathrm{g})}$. In addition, the lower devolatilization temperature observed for SRM indicates that the process could operate at lower temperatures compared to the temperatures needed for utilizing coal.

\section{Devolatilization of Individual Plastics}

Considerable variations in thermal decomposition characteristics of individual plastics have been reported by several researchers [3, 29]. Some plastic such as PE decomposes mainly by release of volatiles, while for some materials, such as PVC and PU, decomposition is accompanied by production of char. Utilization of some individual plastics such as $\mathrm{PE}$ as a reduction agent in iron and steel making has been reported in the literature $[4,11]$. In this study, the devolatilization characteristics and volatile releases from PE, PVC, and PU are studied, to gain a better understanding on the potential of plastic materials as reducing agent. Figures 6,7 , and 8 a show the weight loss, DTG curves, while Figs. 6, 7, and 8b show the evolved volatiles for devolatilizations of the three studied plastics,
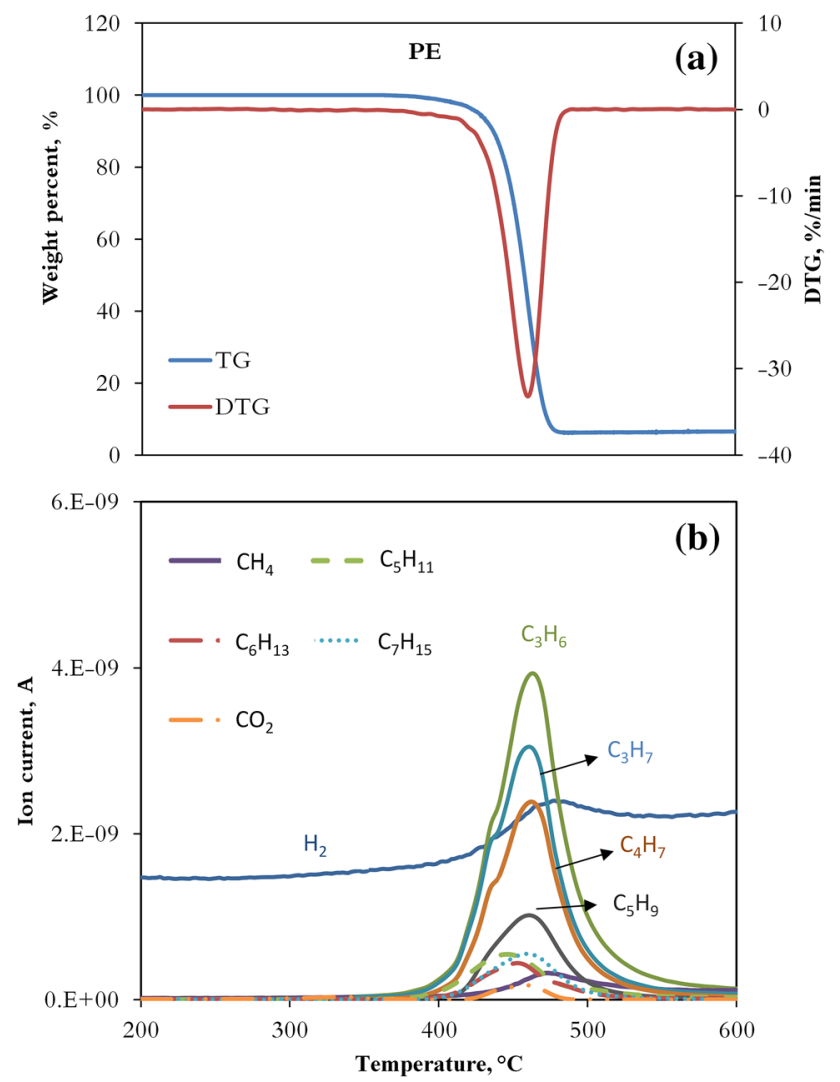

Fig. 6 a TGA, DTG curves of PE devolatilization under argon flow, at heating rate of $10^{\circ} \mathrm{C} / \mathrm{min}$. b Composition of volatiles released as detected by mass spectrometer (Color figure online)
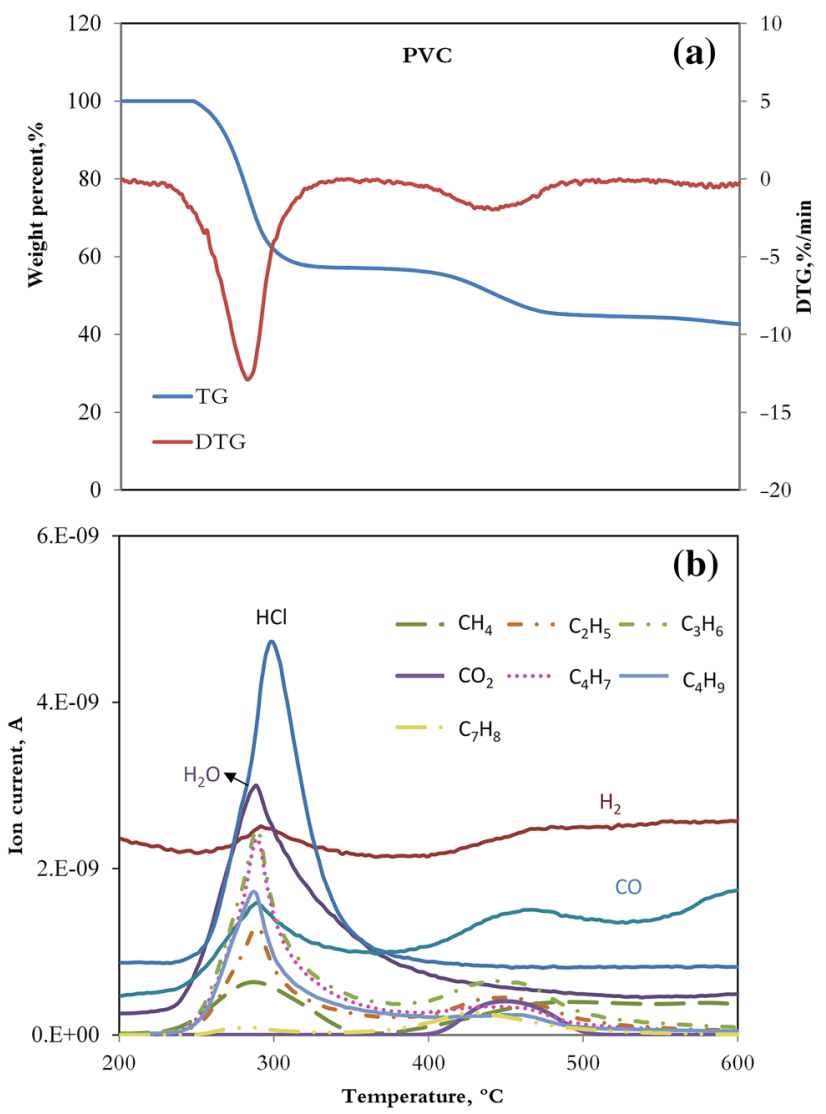

Fig. 7 a TGA, DTG curves of PVC devolatilization under argon flow, at heating rate of $10{ }^{\circ} \mathrm{C} / \mathrm{min}$. b Composition of volatiles released as detected by mass spectrometer (Color figure online)

PE, PVC, and PU. Devolatilization of PE starts at approximately $400{ }^{\circ} \mathrm{C}$, and occurs in one narrow temperature range. The DTG peak observed at $460{ }^{\circ} \mathrm{C}$ is accompanied by release of $\mathrm{H}_{2}$, in addition to hydrocarbons ranging from $\mathrm{C} 1$ to $\mathrm{C} 7$. $\mathrm{PVC}$ decomposes in two distinct stages, which is in agreement with other researchers findings $[16,25]$. In the temperature range of $250-350{ }^{\circ} \mathrm{C}$, corresponding to the first peak of DTG, $\mathrm{HCl}$ is observed. In addition to $\mathrm{HCl}$, other volatiles such as $\mathrm{CO}_{2}, \mathrm{H}_{2} \mathrm{O}$, and hydrocarbons are released in this temperature range. For the second peak of DTG, which occurs in the temperature range of $400-500{ }^{\circ} \mathrm{C}$, the volatiles detected, apart from $\mathrm{HCl}$, are the same as those identified for the previous peak.

The DTG curve for the devolatilization of PU shows two peaks, indicating two stages of devolatilization. The first peak is judged, based on experimental data, to consist of three overlapping peaks. The first overlapping peak at $300{ }^{\circ} \mathrm{C}$ corresponds to releases of $\mathrm{CO}_{2}, \mathrm{CO}$, and $\mathrm{CH}_{4}$. Release of $\mathrm{CO}_{2}$ is due to dimerization of the isocyanate [14]. The second overlapping peak corresponds to releases of $\mathrm{C}_{2} \mathrm{H}_{5} \mathrm{OH}$ and $\mathrm{H}_{2} \mathrm{O}$ at $350{ }^{\circ} \mathrm{C}$, and releases of water vapor and ethanol have also been observed by other researchers [14]. The last overlapping peak was observed at $400{ }^{\circ} \mathrm{C}$, in 

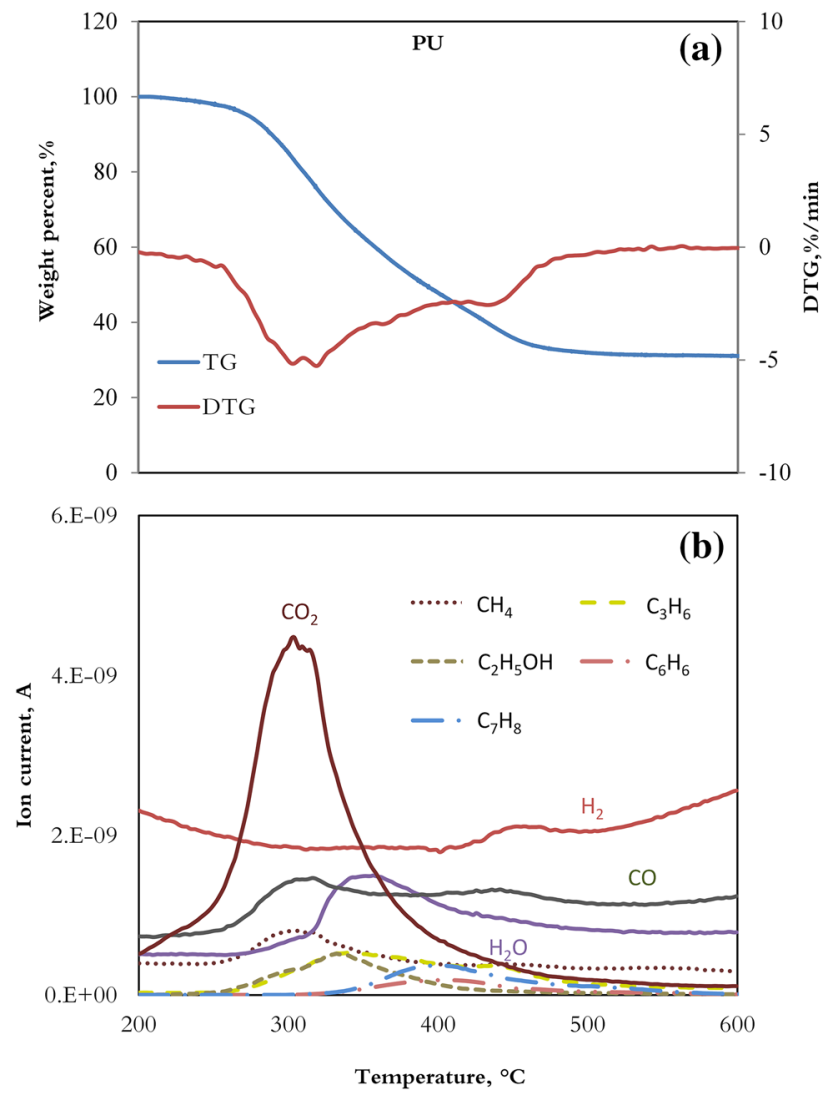

Fig. 8 a TGA, DTG curves of PU devolatilization under argon flow, at heating rate of $10{ }^{\circ} \mathrm{C} / \mathrm{min}$. b Composition of volatiles released as detected by mass spectrometer (Color figure online)

which releases of hydrocarbons such as $\mathrm{C}_{6} \mathrm{H}_{6}$ and $\mathrm{C}_{7} \mathrm{H}_{8}$ were observed. Finally, the last peak (second peak) observed at $450{ }^{\circ} \mathrm{C}$ is accompanied by an increase in the release of $\mathrm{H}_{2}$.

For the metallurgical process, it can be observed that PE decomposes by release of $94 \%$ volatiles, which consist of aliphatic hydrocarbons with low content of carbon. Thus, it is probable that $\mathrm{PE}$ would contribute to reduction just by volatiles. PVC and PU both give rise to hydrocarbons with higher carbon content, which requires higher energy to crack during the process. Devolatilizations of PVC and PU are accompanied by release of $\mathrm{CO}$, which can directly participate in reduction. Furthermore, decompositions of PVC and PU produce char with 12 and $14 \%$ fixed carbon contents, respectively, that can also participate in reduction.

Table 3 summarizes the structures of the studied plastics and the identified released volatiles during their devolatilization. As devolatilization involves chain scission, different mechanisms were observed for these plastics. PE has a simpler structure compared with the two other plastics and is known to devolatilize by random scission of $\mathrm{C}-\mathrm{C}$ bond, forming different molecular weight hydrocarbons. PVC has a slightly more complex structure compared with PE, and two stages during its devolatilization were observed. Formation of $\mathrm{HCl}$ observed for SRM is probably due to the presence of PVC and breaking-up of $\mathrm{C}-\mathrm{Cl}$ bond. PU consists of several different bonds; therefore, its devolatilization involves more stages, which leads to a more complex devolatilization behavior. It can be concluded that even at the level of individual plastics, devolatilization mechanisms are complex.

\section{Devolatilization of Mixed Plastics}

Binary and ternary mixtures give rise to the possibility of modifying the desired properties from individual plastics. Current study shows that the studied plastics decompose differently, and mixing would result in tailored properties. Several researchers have studied the mixture of plastics and have reported their possible interaction [30, 31]; therefore, the mixture of plastics is studied. Binary mixtures of $\mathrm{PE} / \mathrm{PU}, \mathrm{PE} / \mathrm{PVC}$, and $\mathrm{PU} / \mathrm{PVC}$ with the weight proportions of 1:1 were investigated. A calculated curve is constructed based on the assumption that each plastic in the mixture devolatilizes according to the results of this study and free from interaction with other plastics (Fig. 9).

Table 3 Structures of PE, PVC, and PU and the volatiles observed during their devolatilizations

\begin{tabular}{llll}
\hline & Structure & Temperature $\left({ }^{\circ} \mathrm{C}\right)$ & The volatile \\
\hline $\mathrm{PE}$ & & $400-500$ & $\mathrm{C} 1-\mathrm{C} 7$, and $\mathrm{H}_{2} \mathrm{O}, \mathrm{H}_{2}$ \\
$\mathrm{PVC}$ & & $250-350$ & $\mathrm{HCl}$ and $\mathrm{C} 1-\mathrm{C} 7, \mathrm{H}_{2} \mathrm{O} \mathrm{CO}, \mathrm{CO}_{2}$ \\
$\mathrm{C} 1-\mathrm{C} 7$
\end{tabular}



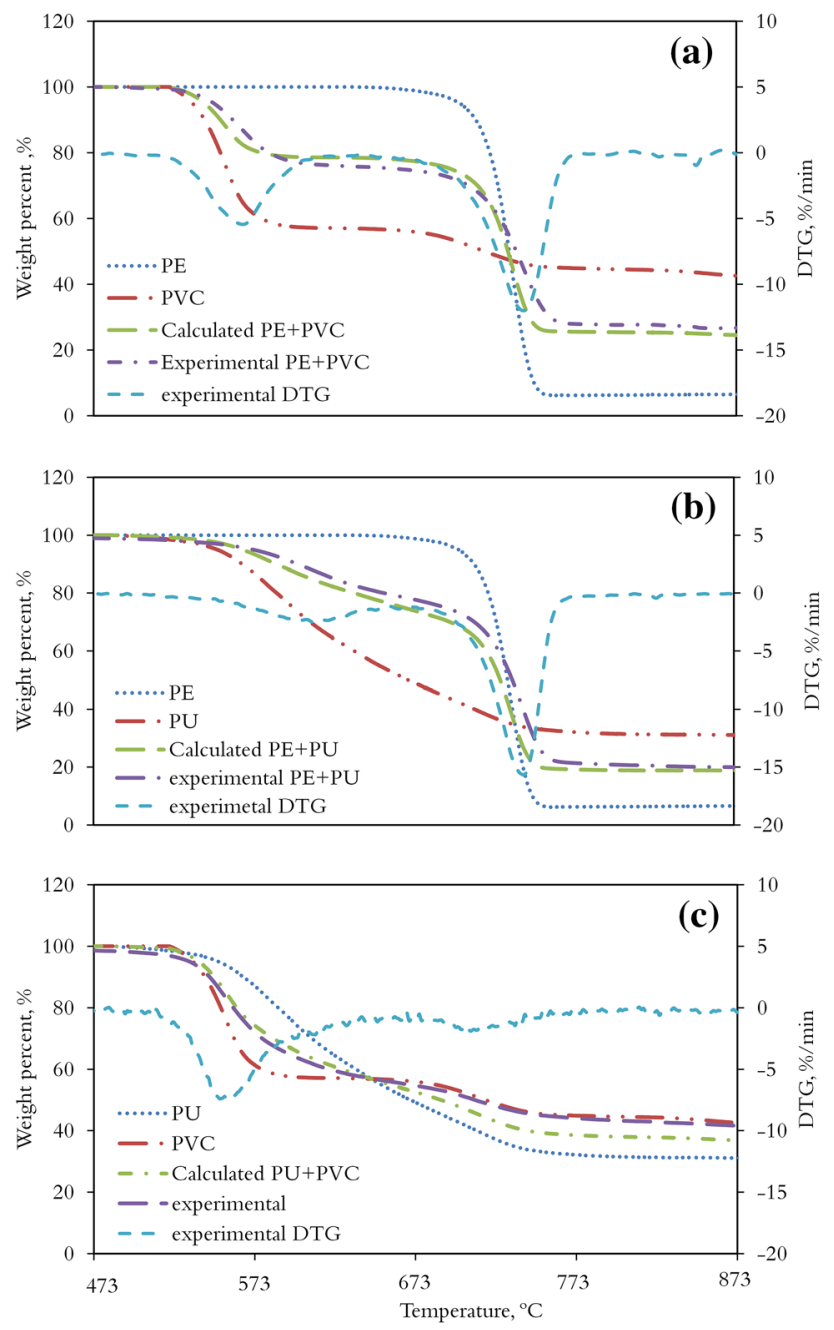

Fig. 9 Calculated and experimental curves of binary mixture of plastics, devolatilization under argon flow at heating rate of $10{ }^{\circ} \mathrm{C} /$ min. a PE/PVC, b PE/PU, c PU/PVC; experimental DTG curve is plotted, showing different stages of devolatilization (Color figure online)

For the PE/PVC and PE/PU mixtures, the experimental devolatilization curves are in good agreement with the calculated ones, although the rates are slightly different. This suggests that these plastics devolatilize without interaction. Miranda et al. [30] studied the vacuum devolatilization of a PE/PVC mixture and also reported similar observations.

Comparison of the experimental curve and the calculated curve for PVC/PU mixture shows a higher amount of char left compared to what has been calculated. The binary mixture shows two stages, indicated by DTG curve. During the first stage, experimental and calculated curves are in agreement. However, in the second stage, the amount of char produced during the experiment is higher compared with the calculated curve, which indicates the possible interaction between the two plastics at this stage. In the second stage, the binary mixture shows similar devolatilization behavior as

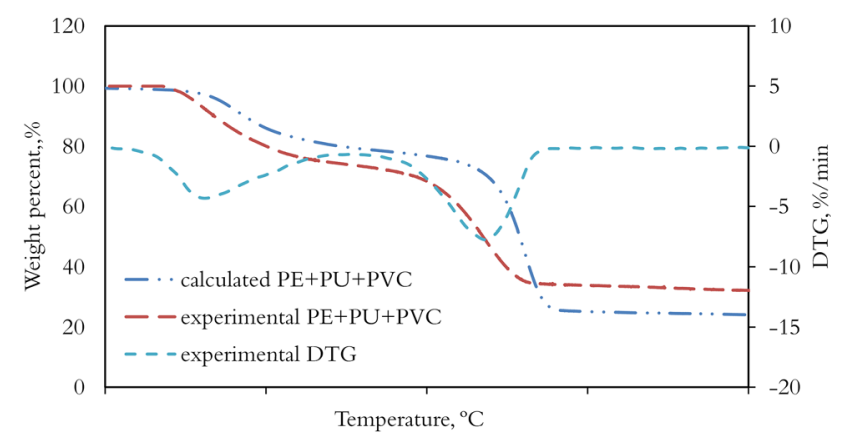

Fig. 10 Calculated and experimental curves of ternary mixture of plastics, devolatilization under argon flow at heating rate of $10{ }^{\circ} \mathrm{C} /$ min, PE/PU/PVC; experimental DTG curve is plotted, showing different stages of devolatilization (Color figure online)

that of PVC. The deviation observed in the second stage is probably related to crosslinking reactions, which is especially important in the formation of char [12]. The higher amount of char observed could be due to the crosslinking (recombination) reaction of the volatiles formed with the remaining structure. In addition, possible bond formation between the two remaining plastics and their structures could also result in a more stable structure and, consequently, higher residual char.

Furthermore, the devolatilization of a ternary mixture of PE, PU, and PVC with a weight ratio of 1:1:1 was studied. A calculated curve is constructed based on the experimental data from devolatilization curves of PU/PVC binary mixture and PE, presented in Fig. 10. This way the interaction between PU/PVC is already considered, and the assumption is that no further interaction would occur between the plastics.

The first stage of devolatilization shows that a higher amount of volatile was released during the experiment than the calculated amount. However, the second stage shows lower experimental volatile release; therefore, a higher amount of char compared with the calculated curve was observed. It has been reported that the nitrogen-containing compounds in PU can contribute to acceleration of PVC dehydrochlorization [32], which can explain the higher rate of devolatilization observed in the initial stage of devolatilization. The experimental rate shows a lower rate in the second devolatilization stage, which is probably related to a change in the extent of crosslinking reaction. Despite the assumption that PE would not interact with the other plastics, addition of PE to binary mixture of PU/PVC led to an observed difference between the calculated and experimental curves. This indicates a possible further interaction between PE and binary mixture.

The study of binary and ternary mixtures shows the complication arising from the interaction between the plastics in the mixture. Although devolatilization mechanisms of individual plastics and to some extent binary 
mixtures are reported in the literature, fewer studies are available for higher numbers of compounds in the mixture. However, considering the different mechanisms involved in devolatilizations of plastics and interactions occurring in the studied mixture, some understanding of the devolatilization mechanism of SRM has been gained. Initially plastics decompose by release of the primary volatiles. The primary volatiles could leave the plastic without further interaction with the other primary volatiles from either the same or different plastics. However, a more probable theory is that the primary volatiles either interact with other primary volatiles released from other plastics or with the remaining structure of plastics. Consequently, in SRM, which contains different types of plastics, and their composition is not always known, there is a high chance of interaction between the plastics, which makes its devolatilization mechanisms complex. In addition, it is known that the inorganic content present in ash such as $\mathrm{Cu}$ and $\mathrm{Fe}$ can have a catalytic effect on devolatilization of plastic material [33]. Furthermore, while the presence of elements such as $\mathrm{Cu}$ restricts utilization of SRM in the blast furnace, in nonferrous bath smelting, the process can be designed in such a way that the inorganic compound can be extracted.

\section{Conclusions}

- Proximate analysis showed that the volatile contents of SRM and individual plastics were higher than that of coal, while their fixed carbon content was lower.

- Ash content of SRM was higher than that of coal, which is reported to have a catalytic effect during devolatilization.

- During SRM devolatilization, volatiles are released in the temperature range of $280-450{ }^{\circ} \mathrm{C}$, and composed of $\mathrm{CO}, \mathrm{H}_{2}$, and hydrocarbons, which have reduction potential, and thus could possibly contribute to reduction reactions.

- The DTG curve and volatiles released during devolatilization of SRM show more stages during SRM devolatilization, due to the heterogeneous nature of SRM.

Thermal decomposition of SRM is studied in comparison with coal, for potential utilization as a substitute to be used as a reducing agent in nonferrous bath smelting processes. The findings of this study show that for SRM to be used as a reducing agent, it is necessary to utilize the evolved volatiles in the process. The devolatilization of SRM occurs in a lower-temperature range compared with coal.
Furthermore, to gain a better understanding on potential utilization of plastic materials as reducing gent, the devolatilizations of three common plastics, namely, PE, PVC, and PU and their mixtures have been studied. PE decomposes by release of $94 \%$ volatiles, which consist of aliphatic hydrocarbons with low carbon number. Thus, it is probable that $\mathrm{PE}$ would contribute to reduction just by volatiles, while PVC and PU produces char with 12 and $14 \%$ fixed carbon contents, respectively, that can also participate in reduction. The binary and ternary mixtures have shown the interaction between the plastics during devolatilization. Thus, it is possible to conclude that during SRM devolatilization, the released volatile from each plastic could interact with volatiles from other plastics.

Acknowledgments Financial supports from Boliden Commercial and Vinnova-supported Strategic innovation program for the Swedish mining and metal producing industry, SIP STRIM are greatly acknowledged. The authors would also like to express their gratitude to Tommy Vikström, Boliden Mineral AB, for his kind collaboration.

Open Access This article is distributed under the terms of the Creative Commons Attribution 4.0 International License (http://crea tivecommons.org/licenses/by/4.0/), which permits unrestricted use, distribution, and reproduction in any medium, provided you give appropriate credit to the original author(s) and the source, provide a link to the Creative Commons license, and indicate if changes were made.

\section{References}

1. Menad N, Kanari N, Guignot S, et al. (2013) Material and energy beneficiation of the automobile shredder residues. In: The Minerals Metals Materials Society-Rewas 2013. Wiley, New York, pp 89-99.

2. Forton O, Harder M, Moles N (2006) Value from shredder waste: ongoing limitations in the UK. Resour Conserv Recycl 46(1):104-113

3. Day M, Cooney J, Touchette-Barrette C, Sheehan S (1999) Pyrolysis of mixed plastics used in the electronics industry. J Anal Appl Pyrolysis 52(2):199-224

4. Sahajwalla V, Zaharia M, Kongkarat S, Khanna R, SahaChaudhury N, O'Kane P (2009) Recycling plastics as a resource for electric arc furnace (EAF) steelmaking: combustion and structural transformations of metallurgical coke and plastic blends. Energy Fuels 24(1):379-391

5. Kantarelis E, Donaj P, Yang W, Zabaniotou A (2009) Sustainable valorization of plastic wastes for energy with environmental safety via high-temperature pyrolysis (HTP) and high-temperature steam gasification (HTSG). J Hazard Mater 167(1):675-684

6. Yang X, Sun L, Xiang J, Hu S, Su S (2013) Pyrolysis and dehalogenation of plastics from waste electrical and electronic equipment (WEEE): a review. Waste Manag 33(2):462-473

7. Babich A, Senk D, Knepper M, Benkert S (2016) Conversion of injected waste plastics in blast furnace. Ironmak Steelmak 43(1):11-21

8. Mirabile D, Pistelli MI, Marchesini M, Falciani R, Chiappelli L (2002) Thermal valorisation of automobile shredder residue: injection in blast furnace. Waste Manag 22(8):841-851 
9. Richards GG, Brimacombe J, Toop G (1985) Kinetics of the zinc slag-fuming process: part I. Industrial measurements. Metall Trans B 16(3):513-527

10. Usachev A, Balasanov A, Lekherzak V, Romenets V (2013) Behaviour of coal in smelting reduction installation. Ironmak Steelmak 27(6):426-431

11. Kim D, Shin S, Sohn S, Choi J, Ban B (2002) Waste plastics as supplemental fuel in the blast furnace process: improving combustion efficiencies. J Hazard Mater 94(3):213-222

12. Beyler CL, Hirschler MM (2002) Thermal decomposition of polymers. SFPE handbook of fire protection engineering, vol 2, pp $110-131$

13. Faravelli T, Bozzano G, Scassa C, Perego M, Fabini S, Ranzi E, Dente M (1999) Gas product distribution from polyethylene pyrolysis. J Anal Appl Pyrolysis 52(1):87-103

14. Lefebvre J, Duquesne S, Mamleev V, Bras ML, Delobel R (2003) Study of the kinetics of pyrolysis of a rigid polyurethane foam: use of the invariant kinetics parameters method. Polym Adv Technol 14(11-12):796-801

15. Rein G, Lautenberger C, Fernandez-Pello AC, Torero JL, Urban DL (2006) Application of genetic algorithms and thermogravimetry to determine the kinetics of polyurethane foam in smoldering combustion. Combust Flame 146(1):95-108

16. Miranda R, Yang J, Roy C, Vasile C (1999) Vacuum pyrolysis of PVC I: kinetic study. Polym Degrad Stab 64(1):127-144

17. Beamish BB (1994) Proximate analysis of New Zealand and Australian coals by thermogravimetry. N Z J Geol Geophys. 37(4):387-392

18. Silverstein RM, Webster FX, Kiemle DJ, Bryce DL (2014) Spectrometric identification of organic compounds. Wiley, New York

19. Zhou L, Wang Y, Huang Q, Cai J (2006) Thermogravimetric characteristics and kinetic of plastic and biomass blends co-pyrolysis. Fuel Process Technol 87(11):963-969

20. Saxena S (1990) Devolatilization and combustion characteristics of coal particles. Prog Energy Combust Sci 16(1):55-94

21. Solomon PR, Hamblen DG, Serio MA, Yu Z, Charpenay S (1993) A characterization method and model for predicting coal conversion behaviour. Fuel 72(4):469-488
22. Yu J, Lucas JA, Wall TF (2007) Formation of the structure of chars during devolatilization of pulverized coal and its thermoproperties: a review. Prog Energy Combust Sci 33(2):135-170

23. Guo Q, Zhang X, Li C, Liu X, Li J (2012) TG-MS study of the thermo-oxidative behavior of plastic automobile shredder residues. J Hazard Mater 209:443-448

24. Vasile C, Brebu MA, Karayildirim T, Yanik J, Darie H (2006) Feedstock recycling from plastic and thermoset fractions of used computers (I): pyrolysis. J Mater Cycles Waste Manage 8(2):99-108

25. Hall WJ, Williams PT (2006) Fast pyrolysis of halogenated plastics recovered from waste computers. Energy Fuels 20(4):1536-1549

26. Williams EA, Williams PT (1997) Analysis of products derived from the fast pyrolysis of plastic waste. J Anal Appl Pyrolysis 40:347-363

27. Bodénan F, Menad N, Wavrer P, Guignot S, Quatravaux T, Russo $P$ (2013) Recycling of automotive shredder residues (ASR) in iron-and steelmaking furnaces. Ironmak Steelmak 39(7):493-497

28. Ghosh D, Roy A, Ghosh A (1986) Reduction of ferric oxide pellets with methane. Trans Iron Steel Inst Jpn 26(3):186-193

29. Menad N, Björkman B, Allain EG (1998) Combustion of plastics contained in electric and electronic scrap. Resour Conserv Recycl 24(1):65-85

30. Miranda R, Yang J, Roy C, Vasile C (2001) Vacuum pyrolysis of commingled plastics containing PVC I: kinetic study. Polym Degrad Stab 72(3):469-491. doi:10.1016/S0141-3910(01)00048-9

31. Sakata Y, Uddin MA, Koizumi K, Murata K (1996) Thermal degradation of polyethylene mixed with poly(vinyl chloride) and poly(ethyleneterephthalate). Polym Degrad Stab 53(1):111-117

32. Kolesov S, Neboilova I, Steklova A, Vladychina S, Minsker K (1989) Kinetics of thermal degradation of poly(vinyl chloride)polyurethane blends. Polym Sci USSR 31(2):476-480

33. Blazso M (1999) Thermal decomposition of polymers modified by catalytic effects of copper and iron chlorides. J Anal Appl Pyrolysis 51(1):73-88 